\title{
On the prevention of kidney uptake of radiolabeled DARPins
}

Mohamed Altai ${ }^{1 \dagger}$, Javad Garousi ${ }^{1 \dagger}$, Sara S. Rinne ${ }^{2}$, Alexey Schulga ${ }^{3}$, Sergey Deyev ${ }^{3,4,5}$ and Anzhelika Vorobyeva ${ }^{1,4^{*}}$ (D)

\begin{abstract}
Background: Designed ankyrin repeat proteins (DARPins) are small engineered scaffold proteins (14-18 kDa) that demonstrated promising tumor-targeting properties in preclinical studies. However, high renal accumulation of activity for DARPins labeled with residualizing labels is a limitation for targeted radionuclide therapy. A better understanding of the mechanisms behind the kidney uptake of DARPins could aid the development of strategies to reduce it. In this study, we have investigated whether the renal uptake of $\left[{ }^{99 \mathrm{~m}} \mathrm{Tc}\right] \mathrm{Tc}(\mathrm{CO})_{3}-\mathrm{G} 3$ DARPin could be reduced by administration of compounds that act on various parts of the reabsorption system in the kidney.

Results: Co-injection of lysine or Gelofusine was not effective for the reduction of kidney uptake of $\left.{ }^{99 \mathrm{~m}} \mathrm{Tc}\right] \mathrm{Tc}(\mathrm{CO})_{3^{-}}$ G3. Administration of sodium maleate before the injection of $\left.{ }^{99 \mathrm{~m}} \mathrm{Tc}\right] \mathrm{Tc}(\mathrm{CO})_{3}-\mathrm{G} 3$ reduced the kidney-associated activity by $60.4 \pm 10.3 \%$, while administration of fructose reduced it by $46.9 \pm 7.6 \%$ compared with the control. The decrease in the kidney uptake provided by sodium maleate was also observed for $\left.{ }^{99 \mathrm{~m}} \mathrm{Tc}\right] \mathrm{Tc}(\mathrm{CO})_{3}{ }_{3}{ }_{2} 29$ DARPin. Preinjection of colchicine, probenecid, mannitol, or furosemide had no effect on the kidney uptake of $\left[{ }^{99 \mathrm{~m}} \mathrm{Tc}\right] \mathrm{Tc}(\mathrm{CO})_{3}-\mathrm{G} 3$. Kidney autoradiography showed mainly cortical accumulation of activity for all studied groups. Conclusion: Common clinical strategies were not effective for the reduction of kidney uptake of $\left.{ }^{99 \mathrm{~m}} \mathrm{Tc}\right] \mathrm{Tc}(\mathrm{CO})_{3}-\mathrm{G} 3$. Both fructose and maleate lower the cellular ATP level in the proximal tubule cells and their reduction of the kidney reuptake indicates the involvement of an ATP-driven uptake mechanism. The decrease provided by maleate for both G3 and 9_29 DARPins indicates that their uptake proceeds through a mechanism independent of DARPin structure and binding site composition.
\end{abstract}

Keywords: DARPin, Radiolabel, Kidney, Reabsorption, Renal uptake

\section{Background}

Development of targeted radiopharmaceuticals for precise diagnosis and efficient therapy of cancer requires high target selectivity, low uptake in normal organs and tissues, and fast clearance. A new class of targeting molecules, engineered scaffold proteins (ESPs), is promising agents for tumor-targeted delivery of radionuclides [1]. Several types of ESPs, such as affibody molecules [2], ADAPTs [3], and DARPins [4-9] demonstrated efficient tumor targeting and high contrast of radionuclide imaging in preclinical studies. DARPins are built of 4-6 repeat modules of 33 amino acids and have a molecular

\footnotetext{
* Correspondence: anzhelika.vorobyeva@igp.uu.se

${ }^{+}$Mohamed Altai and Javad Garousi contributed equally to this work.

${ }^{1}$ Department of Immunology, Genetics and Pathology, Uppsala University,

SE-75185 Uppsala, Sweden

${ }^{4}$ National Research Tomsk Polytechnic University, Tomsk, Russia

Full list of author information is available at the end of the article
}

weight of $14-18 \mathrm{kDa}$ [10]. Their small size and high affinity enable good extravasation, deep penetration, and high accumulation and retention in tumors. Due to the rapid clearance from the blood and normal tissues, they provide high imaging contrast several hours after injection and could be potentially suitable for tumor-targeted radionuclide delivery. However, similarly to other ESPs, DARPins have a high accumulation of activity in the kidneys. Having molecular weight lower than $60 \mathrm{kDa}$, DARPins are efficiently filtered through the glomerular membrane into the primary urine, and then reabsorbed and internalized by the proximal tubule cells. After proteolytic degradation in lysosomes, radiolabeled catabolites either diffuse out of the cells back to the blood (non-residualizing labels) or remain inside the cells (residualizing labels). Typically, radiometals (e.g., lutetium177, yttrium-90, actinium-225) attached to a targeting molecule by macrocyclic chelators provide residualizing 
labels. Radiohalogens (e.g., iodine-131) attached directly to tyrosine or by halobenzoate linkers to lysine provide non-residualizing labels, although some residualizing radiohalogen labels have been developed [11].

For targeted radionuclide therapy, it is necessary to deliver a high local absorbed dose to tumors and low absorbed doses to normal tissues to be effective and safe. As radiolabeled targeting molecules are taken up not only in tumors but also in excretory organs, high tumorto-normal organ ratios are required. Retention of activity in tumors and in normal organs depends on the rate of receptor internalization and residualizing properties of the label. In the case of rapid internalization in tumors, residualizing labels are preferable, as they provide longer retention of activity and higher absorbed dose to the tumor than non-residualizing labels [11]. However, internalization of ESP such as affibody molecules, ADAPTs, and DARPins is relatively slow, and typically less than $20 \%$ are internalized during $24 \mathrm{~h}[2,3,6]$. In this case, good tumor retention is mainly dependent on high affinity to a molecular target, and residualizing properties of a label are less critical for good retention of activity in tumors. The internalization in the kidneys is always rapid and may lead to high renal accumulation of activity in the case of efficient reabsorption of a targeting protein or peptide and the use of a residualizing label. This puts a limit on the amount of activity administered to a patient. In the case of non-residualizing labels for ESP, the renal activity decreases rapidly due to leakage of radiocatabolites $[2,3,6,9]$.

Targeted radionuclide therapy using radiometallabeled peptides or small proteins is mainly limited by radionephrotoxicity. In order to deliver the required dose to tumors without exceeding the limiting dose to the kidneys (23 Gy), several strategies have been developed. The use of labeling approaches that provide nonresidualizing radiocatabolites, such as radioiodination [5, 6] or the use of some peptide-based chelators for rhenium radioisotopes and technetium-99m [12-17], was shown to decrease the retention of activity in the kidneys by several folds and to improve tumor-to-kidney ratios. Another effective strategy is the fusion of an ESP to an albumin-binding domain (ABD). ABD binds to serum albumin, which increases the hydrodynamic radius above the size of the glomerular filter in the kidneys and reduces glomerular filtration. This approach was not only effective for the reduction of kidney uptake but also improved the tumor uptake due to increased circulation time of the targeting protein $[18,19]$. Pretargeting is another effective strategy for an overall reduction of activity uptake in normal organs [20]. Low accumulation of the radiolabeled secondary agent in the kidneys is a prerequisite for successful pretargeting. Pretargeting systems based on oligonucleotides [21, 22] and bioorthogonal chemistry [23, 24] were evaluated in vivo in preclinical studies, while avidin-biotin and bispecific antibody-hapten [25] were translated to clinical trials $[26,27]$.

In diagnostic imaging, high kidney uptake of activity could potentially preclude visualization of small metastasis in the peritoneal region [28]. However, a clinical study with $\left[{ }^{111} \mathrm{In}\right] \mathrm{In}$-labeled affibody showed that modern SPECT cameras allow for imaging of metastasis in the adrenal glands close to the kidneys [29]. Nonetheless, reduction in radioactivity uptake in normal organs is generally desirable in order to decrease dose to the patient.

The above-described approaches for the reduction of kidney uptake are based on modulation of physicochemical properties of a targeting protein, radiolabel, and are specifically tailored to a given radiolabeled tracer. Therefore, it is of interest to investigate whether a general pharmacological approach could be used to lower the uptake of peptide- and protein-based radiopharmaceuticals in the kidneys.

Common clinical strategies for kidney protection during peptide receptor radionuclide therapy (PRRT) with somatostatin analogs include infusion of positively charged basic amino acids (lysine, arginine) and Gelofusine [30, 31]. Gelofusine consists of succinylated bovine gelatin and is used in clinics as a plasma expander. Both lysine and Gelofusine are ligands for megalin, an endocytic receptor in the proximal tubular cells. The megalin system is involved in the rescue of peptides and proteins from the primary urine back to the blood [32]. However, not all peptides and proteins are rescued by this system. For example, it was previously shown for affibody molecules that the megalin system was not involved in their reabsorption in the kidneys [33]. On the other hand, for nanobodies, another type of small targeting proteins, megalin was shown to take part in their reuptake, which could be inhibited by co-infusion of lysine and Gelofusine [34].

A number of other compounds were additionally investigated to reduce the renal uptake of $\left[{ }^{111} \mathrm{In}\right] \mathrm{In}$-labeled somatostatin analogs. Rolleman et al. found that the administration of colchicine and fructose was effective for the reduction of kidney uptake of $\left[{ }^{111} \mathrm{In}\right]$ In-DTPAoctreotide [35]. Melis et al. demonstrated that sodium maleate also reduced the kidney uptake of $\left[{ }^{111} \mathrm{In}\right] \mathrm{In}$ DTPA-octreotide [36]. Stahl et al. studied the effect of probenecid, furosemide, and mannitol on renal uptake of [ $\left.{ }^{111} \mathrm{In}\right]$ In-DOTATOC [37].

These above-discussed pharmacological options to reduce reabsorption in the kidneys have not been previously investigated for DARPins. Therefore, the present study was designed to evaluate the ability of clinically used lysine and Gelofusine to inhibit the renal 
accumulation of radiolabeled DARPins. In order to get a better understanding of the mechanisms behind the renal uptake of radiolabeled DARPins, we also evaluated the effect of several other compounds (sodium maleate, colchicine, mannitol, furosemide, probenecid, and fructose) that were reported to interfere with the reuptake and retention of protein-based agents in the proximal tubular cells in the kidneys.

\section{Methods \\ General}

Technetium-99m was eluted as pertechnetate from the Ultra-TechneKow generator (Mallinckrodt, The Netherlands) with sterile $0.9 \%$ sodium chloride. The CRS (Center for Radiopharmaceutical Sciences) kits for the production of tricarbonyl technetium were purchased from the CRS (PSI, Switzerland). Sodium maleate, D-fructose, colchicine, probenecid, and L-lysine were purchased from Sigma (Sigma-Aldrich, USA). Furosemid (Takeda Pharma AB, Sweden), mannitol (Fresenius Kabi AB, Sweden), and Gelofusine (B. Braun Melsungen AG, Germany) were purchased as solutions for injections. The anti-human epidermal growth factor receptor 2 (anti-HER2) DARPins G3 and 9_29 were produced in E. coli strain BL21(DE3) as described previously $[5,6]$. DARPin G3 consists of four ankyrin repeats $(14 \mathrm{kDa})$, and DARPin 9_29 consists of five ankyrin repeats (18 kDa). DARPin 9_29 binds to subdomain I of the HER2 receptor, while DARPin G3 binds to subdomain IV [38]. Amino acids involved in the interaction between 9_29 and HER2:I are different from those involved in the interaction between G3 and HER2:IV [38]. Both DARPins have a hexahistidine tag at C-terminus for sitespecific labeling with tricarbonyl technetium. iTLC analysis was performed using iTLC silica gel strips (Varian, Lake Forest, USA). The radioactivity distribution along iTLC strips was measured using a Cyclone phosphor system and analyzed by the OptiQuant image analysis software (both from PerkinElmer, USA). Radioactivity in the organs and tissues was measured using an automated gamma-spectrometer with a $\mathrm{NaI}$ (TI) detector (1480 Wizard, Wallac, Finland).

\section{Radiolabeling of DARPins}

Site-specific radiolabeling of hexahistidine-containing 9 29 and G3 DARPins with $\left[\left[{ }^{99 \mathrm{~m}} \mathrm{Tc}\right] \mathrm{Tc}(\mathrm{CO})_{3}\right]^{+}$to obtain a residualizing label was performed as described earlier [6]. Purification of radiolabeled DARPins by sizeexclusion chromatography was performed using NAP-5 columns (GE Healthcare, UK) pre-equilibrated and eluted with PBS. Radiochemical yield and purity were measured using radio-iTLC in PBS.

\section{Animal studies}

Female NMRI mice (10 weeks old) were housed in standard conditions at $22{ }^{\circ} \mathrm{C}$, with laboratory food and water provided ad libitum. Mice had an adaptation period of 1 week prior to the start of experiments. For biodistribution studies, 48 mice were randomized in 12 groups to include 4 animals per group. The average animal weight at the time of experiments was $24.9 \pm 1.4 \mathrm{~g}$. To test the effect of various compounds on the kidney uptake of ${ }^{99 \mathrm{~m}}$ Tc-labeled DARPin G3, mice were treated with 1 compound per group according to Table 1 before administration of $\left[{ }^{99 \mathrm{~m}} \mathrm{Tc}\right] \mathrm{Tc}(\mathrm{CO})_{3}-\mathrm{G} 3$, except lysine and Gelofusine, which were co-administered with $\left[{ }^{99 \mathrm{~m}} \mathrm{Tc}\right] \mathrm{Tc}(\mathrm{CO})_{3}-\mathrm{G} 3$. The effect of maleate administration on the kidney uptake was additionally studied for DARPin 9_29 (a variant with 5 ankyrin repeats, $18 \mathrm{kDa}$ ). Radiolabeled DARPins G3 (60 kBq; 0.14 nmol, $2.0 \mu \mathrm{g}$ ) or 9_29 (60 kBq; $0.14 \mathrm{nmol}, 2.5 \mu \mathrm{g})$ in $100 \mu \mathrm{L}$ of $1 \% \mathrm{BSA}$ in $\mathrm{PBS} /$ mouse were administered i.v. The injected amount of protein was adjusted using a corresponding nonlabeled DARPin. At $4 \mathrm{~h}$ p.i. of ${ }^{99 \mathrm{~m}}$ Tc-labeled DARPins, mice were anesthetized by an i.p. injection of ketamine and xylazine solution and sacrificed by heart puncture. Blood was collected with a heparinized syringe, organs were collected and weighed, and activity was measured using a gamma spectrometer. The data was corrected for decay, and percent of ID/g of sample was calculated, except for GI tract and carcass where \%ID per whole sample was calculated.

\section{Autoradiography}

After the gamma spectrometer measurement, two pairs of kidneys were taken from each group for autoradiography. The kidneys were embedded in the OCT cryomedium, frozen at $-80{ }^{\circ} \mathrm{C}$, cut in serial sections $(30-\mu \mathrm{m}$ thick) using a cryomicrotome, and thaw-mounted on glass slides. For the digital autoradiography, the slides with sections were put in an X-ray cassette and exposed to phosphor screens overnight. The screens were scanned on a Cyclone Storage Phosphor System at a resolution of $600 \mathrm{dpi}$ and analyzed using the OptiQuant software.

\section{Statistical analysis}

Statistical analysis of data was performed using GraphPad Prism (Prism 7 for Windows, GraphPad Software, USA). When two sets were compared (control and maleate-treated group for 9_29), an unpaired two-tailed $t$ test was used to find the significant differences. For comparison of three or more sets of data, a one-way ANOVA test with Bonferroni correction for multiple comparisons was applied. 
Table 1 List of compounds that were administered to mice before injections of radiolabeled DARPins

\begin{tabular}{|c|c|c|c|c|c|}
\hline Compound & $\begin{array}{l}\text { Suggested mechanism of action in the } \\
\text { kidney }\end{array}$ & $\begin{array}{l}\text { Route of } \\
\text { administration }\end{array}$ & $\begin{array}{l}\text { Administration respective to } \\
\text { the radiolabeled DARPin }\end{array}$ & Dose & $\mathrm{LD}_{50}$ \\
\hline Lysine & Blocks megalin ligand-binding domains & i.v. & Co-injection & $1200 \mathrm{mg} / \mathrm{kg}$ & 4000 mg/kg (i.p., rat) \\
\hline Gelofusine & Blocks megalin ligand-binding domains & i.v. & Co-injection & 160 mg/kg & $\mathrm{n} / \mathrm{a}$ \\
\hline $\begin{array}{l}\text { Sodium } \\
\text { maleate }\end{array}$ & Inhibits ATP-mediated endocytosis & i.v. & 5 min before & 480 mg/kg & $\begin{array}{l}600 \mathrm{mg} / \mathrm{kg} \text { (i.p., rat) } \\
3380 \\
\mathrm{mg} / \mathrm{kg} \text { (oral, rat) }\end{array}$ \\
\hline Mannitol & $\begin{array}{l}\text { Diuretic, reduces contact time with } \\
\text { scavenger receptors }\end{array}$ & i.v. & 5 min before & 480 mg/kg & 7470 mg/kg (i.v., mouse) \\
\hline Furosemide & $\begin{array}{l}\text { Diuretic, reduces contact time with } \\
\text { scavenger receptors }\end{array}$ & i.v. & 5 min before & $3 \mathrm{mg} / \mathrm{kg}$ & 800 mg/kg (i.p., rat) \\
\hline Fructose & Inhibits ATP-mediated endocytosis & i.p. & 5 min before & $\begin{array}{l}10,800 \mathrm{mg} / \mathrm{kg} \\
(60 \mathrm{mmol} / \mathrm{kg})\end{array}$ & $\begin{array}{l}15,000 \mathrm{mg} / \mathrm{kg} \\
(83 \mathrm{mmol} / \mathrm{kg})\end{array}$ \\
\hline Probenecid & $\begin{array}{l}\text { Reduces renal excretion of drugs by } \\
\text { inhibiting organic anion transporter }\end{array}$ & i.p. & $1 \mathrm{~h}$ before & $24 \mathrm{mg} / \mathrm{kg}$ & 1000 mg/kg (i.p., mouse) \\
\hline Colchicine & $\begin{array}{l}\text { Inhibits recycling of megalin by disrupting } \\
\text { microtubules }\end{array}$ & i.p. & $5 \mathrm{~h}$ before & $1.2 \mathrm{mg} / \mathrm{kg}$ & 1.6 mg/kg (i.p., mouse) \\
\hline
\end{tabular}

\section{Results}

DARPins 9_29 and G3 were radiolabeled with $\left[{ }^{99 \mathrm{~m}} \mathrm{Tc}\right] \mathrm{Tc}(\mathrm{CO})_{3}$ with $52 \%$ and $57 \pm 11 \%$ radiochemical yield, respectively, and purified to provide a radiochemical purity over $97 \%$.

The effect of the administration of various compounds on biodistribution of $\left[{ }^{99 m} \mathrm{Tc}\right] \mathrm{Tc}(\mathrm{CO})_{3}-\mathrm{G} 3$ was studied in mice at $4 \mathrm{~h}$ p.i. Female NMRI mice were first injected with either sodium maleate, mannitol, furosemide, mannitol, probenecid, or colchicine before the injection of $\left[{ }^{99 \mathrm{~m}} \mathrm{Tc}\right] \mathrm{Tc}(\mathrm{CO})_{3}-\mathrm{G} 3$ as described in Table 1 . To study the effects of lysine and Gelofusine, they were coadministered with $\left[{ }^{99 \mathrm{~m}} \mathrm{Tc}\right] \mathrm{Tc}(\mathrm{CO})_{3}-\mathrm{G} 3$. The control group received a single injection of $\left[{ }^{99 \mathrm{~m}} \mathrm{Tc}\right] \mathrm{Tc}(\mathrm{CO})_{3}-\mathrm{G} 3$.

The data for renal activity uptake after the administration of $\left[{ }^{99 m} \mathrm{Tc}\right] \mathrm{Tc}(\mathrm{CO})_{3}-\mathrm{G} 3$ is summarized in Fig. 1a.
Maleate caused a selective 2.5-fold reduction of activity uptake in the kidneys $(73.5 \pm 19.1 \% \mathrm{ID} / \mathrm{g})$ compared with the control group $(185.4 \pm 24.3 \% \mathrm{ID} / \mathrm{g})$; however, no significant $(p>0.05$, one-way ANOVA test) differences in the uptake in other organs or tissues were observed. Fructose administration also decreased the kidney uptake of $\left[{ }^{99 \mathrm{~m}} \mathrm{Tc}\right] \mathrm{Tc}(\mathrm{CO})_{3}-\mathrm{G} 3$ approximately two times $(98.5 \pm 14.0 \% \mathrm{ID} / \mathrm{g})$ in comparison with the control. However, the retention of activity in other organs and the carcass was higher than in control (Table 2). The administration of colchicine did not affect the kidney uptake, but the uptake in other organs and tissues was significantly $(p<0.05$, one-way ANOVA test) different from the control. No significant $(p>0.05$, one-way ANOVA test) differences in the activity uptake in the blood, liver, spleen, or GI
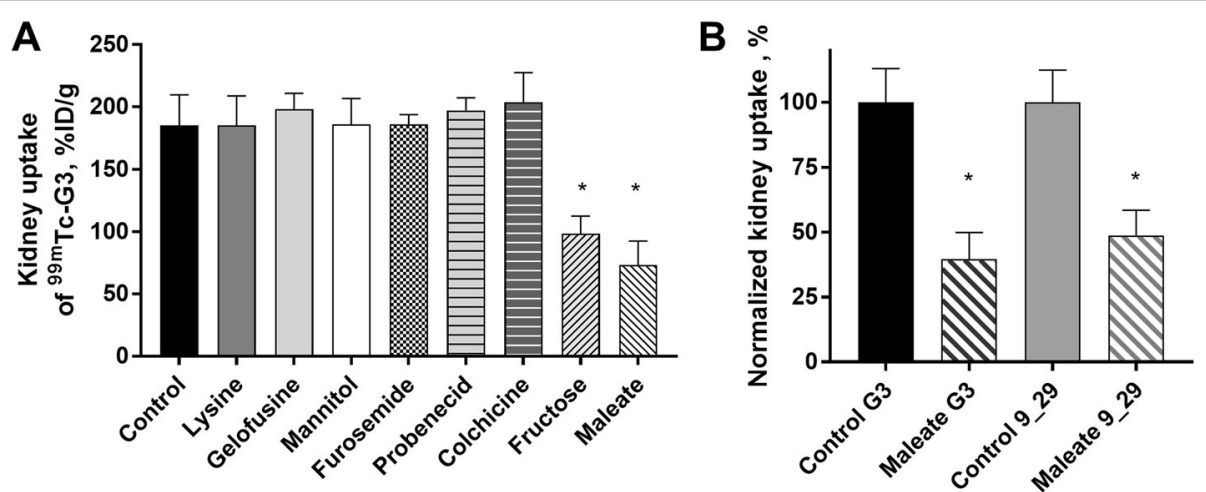

Fig. 1 Kidney uptake of radiolabeled DARPins in female NMRI mice at $4 \mathrm{~h}$ pi. a The effect of different compounds on the kidney uptake of $\left[{ }^{99 \mathrm{~m}} \mathrm{Tc}\right] \mathrm{T} c(\mathrm{CO})_{3}-\mathrm{G} 3 \mathrm{in} \% \mathrm{ID} / \mathrm{g}$. An asterisk marks a significant difference from the control ( ${ }^{*} p<0.0001$, one-way ANOVA test). Data are presented as the average of mice \pm SD, for the control—as the average of eight mice \pm SD. $\mathbf{b}$ The kidney uptake of both radiolabeled DARPins $\left[{ }^{99 m} \mathrm{Tc}\right] \mathrm{TC}(\mathrm{CO})_{3^{-}}$ $\mathrm{G} 3$ and $\left[{ }^{99 \mathrm{~m}} \mathrm{Tc}\right] \mathrm{Tc}(\mathrm{CO})_{3}-9 \_29$ was decreased when maleate was administered 5 min before the DARPins. An asterisk marks a significant difference from the control ( ${ }^{*} p<0.001$, unpaired $t$ test). Data are presented as average from four mice \pm SD 
Table 2 Biodistribution of $\left[{ }^{99 m} \mathrm{Tc}\right] \mathrm{Tc}(\mathrm{CO})_{3}-\mathrm{G} 3$ in NMRI mice 4 h p.i. alone (control) or after administration of compounds

\begin{tabular}{|c|c|c|c|c|c|c|}
\hline & Blood & Salivary glands & Liver & Spleen & Gl tract & Carcass \\
\hline Control & $0.33 \pm 0.04$ & $0.7 \pm 0.2$ & $3.3 \pm 0.3$ & $0.8 \pm 0.2$ & $4 \pm 1$ & $9 \pm 1$ \\
\hline Lysine & $0.28 \pm 0.03$ & $0.6 \pm 0.1$ & $3.0 \pm 0.2$ & $0.6 \pm 0.1$ & $4 \pm 1$ & $7 \pm 1$ \\
\hline Gelofusine & $0.29 \pm 0.04$ & $0.7 \pm 0.2$ & $2.9 \pm 0.4$ & $0.6 \pm 0.1$ & $3.4 \pm 0.2$ & $8 \pm 1$ \\
\hline Mannitol & $0.31 \pm 0.04$ & $0.8 \pm 0.2$ & $3.6 \pm 0.3$ & $0.8 \pm 0.1$ & $3.9 \pm 0.3$ & $9.4 \pm 0.4$ \\
\hline Furosemide & $0.33 \pm 0.02$ & $0.9 \pm 0.1$ & $3.3 \pm 0.3$ & $0.8 \pm 0.1$ & $4 \pm 1$ & $10.1 \pm 0.3$ \\
\hline Probenecid & $0.32 \pm 0.06$ & $0.7 \pm 0.1$ & $3.2 \pm 0.2$ & $0.9 \pm 0.1$ & $4 \pm 1$ & $8 \pm 1$ \\
\hline Colchicine & $0.44 \pm 0.04^{*}$ & $0.5 \pm 0.1$ & $1.9 \pm 0.3^{*}$ & $1.2 \pm 0.2^{*}$ & $2.5 \pm 0.4^{*}$ & $6.9 \pm 0.3$ \\
\hline Fructose & $0.8 \pm 0.1^{*}$ & $1.9 \pm 0.4^{*}$ & $7.0 \pm 1.0^{*}$ & $1.9 \pm 0.1^{*}$ & $7 \pm 1^{*}$ & $20 \pm 2^{*}$ \\
\hline Maleate & $0.33 \pm 0.05$ & $0.6 \pm 0.1$ & $3.0 \pm 0.5$ & $0.7 \pm 0.2$ & $3.4 \pm 0.2$ & $9 \pm 1$ \\
\hline
\end{tabular}

Data are presented as average from four mice \pm SD, for the control-as average from eight mice \pm SD. Uptake is shown in \%ID/g, except for GI tract and carcass, which is shown in \%ID per whole sample. An asterisk marks a significant difference between the control and the treated group ( ${ }^{*} p<0.01$, one-way ANOVA test)

tract were observed between the control and other treatment groups.

To study whether the effect of maleate administration on the kidney uptake was specific for the G3 DARPin scaffold, the same experiment was repeated using

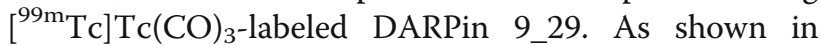
Fig. 1b, maleate also significantly $(p<0.05$, t test) decreased the kidney uptake of activity compared with the non-treated control.

The average mouse weight was $24.9 \pm 1.4 \mathrm{~g}$, the average kidney weight was $264 \pm 25 \mathrm{mg}$. The mice or kidney weights did not differ significantly $(p>0.05$, one-way ANOVA test) between the groups. Representative autoradiograms of the kidney sections of mice injected with $\left[{ }^{99 \mathrm{~m}} \mathrm{Tc}\right] \mathrm{Tc}(\mathrm{CO})_{3}-\mathrm{G} 3$ from the control and treated groups are shown in Fig. 2. For all the studied groups, the activity was mainly localized in the renal cortex.

\section{Discussion}

DARPins, a type of engineered scaffold proteins, are potentially promising vehicles for targeted delivery of radionuclides to cancer-associated molecular abnormalities. The small size of DARPins enables good extravasation into tissues, fast accumulation in tumors, and rapid clearance from the blood, providing high tumor-to-organ ratios several hours after injection. However, the majority of DARPin-associated activity is retained in the kidneys during the renal clearance. Peptides and proteins with the mass below approximately $60 \mathrm{kDa}$ are efficiently filtered through the glomerular membranes and reabsorbed in proximal tubule cells of the kidney. After binding to a receptor, they are internalized by endocytosis and transported to the lysosomes [39]. In the lysosomes, the radiolabeled proteins undergo lysosomal degradation, which leads to the formation of small fragments (catabolites) [40]. Depending on the nature of the radionuclide and properties of the label, the radiocatabolites are either retained inside the cells, e.g., for residualizing labels, or excreted, e.g., for nonresidualizing labels.

One way to reduce the renal retention of activity is to use non-residualizing labels. The anti-HER2 DARPins 9 29 and G3 labeled with non-residualizing iodine labels demonstrated 30 times lower activity in the kidneys compared with residualizing tricarbonyl technetium$99 \mathrm{~m}$ labels $6 \mathrm{~h}$ after injection $[5,6]$. The rapid internalization of DARPins and excretion of non-residualizing labels in the kidneys and liver in comparison with slow internalization in tumor cells enabled high tumor-toorgan ratios. Thus, for non-residualizing labels, the kidneys could act as a major depot of activity, releasing it back to the blood circulation. Radioiodine catabolites excreted from the kidneys to the circulation are taken up in NaI-expressing organs, e.g., thyroid and stomach.

\section{A $\rightarrow 413 \quad$ B (3) 0 C 6

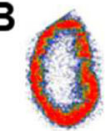
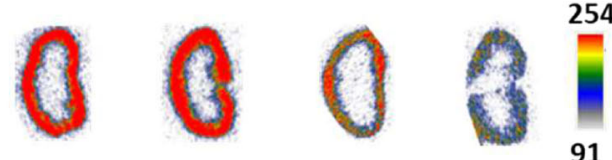

Control Lysine Gelofusine Probenecid Furosemide Control Mannitol Colchicine Fructose Maleate

Fig. 2 Representative ex vivo autoradiograms of the kidney sections. NMRI mice were pre- or co-injected with lysine, Gelofusine, probenecid, furosemide (a) and mannitol, colchicine, fructose, maleate (b), and $\left.{ }^{99 \mathrm{~m}} \mathrm{Tc}\right] \mathrm{Tc}(\mathrm{CO})_{3}-\mathrm{G} 3$ and sacrificed at $4 \mathrm{~h}$ pi. The control group was injected with $\left[{ }^{99 \mathrm{~m}} \mathrm{Tc}\right] \mathrm{TC}(\mathrm{CO})_{3}-\mathrm{G} 3$ only 
In order to prevent the accumulation of activity in these organs, we attempted to optimize the non-residualizing properties of the iodine label. In the first study, sitespecific attachment of iodo-((hydroxyphenyl)ethyl) maleimide (HPEM) label via a GGGC linker indeed decreased the activity uptake in the kidneys [8]. However, a switch of renal to hepatobiliary excretion of DARPin was observed, which was undesirable. In the second study, the use of para-iodobenzoate (PIB) efficiently decreased the accumulation of activity in NaI-expressing organs without affecting the tumor targeting [9]. Due to stronger residualizing properties of the $\left[{ }^{125} \mathrm{I}\right] \mathrm{I}-\mathrm{PIB}-\mathrm{label}$, the retention of activity in the kidneys at $3 \mathrm{~h}$ p.i. was higher than that for the direct labeling; however, the renal activity rapidly decreased by $6 \mathrm{~h}$ p.i.

Another way to reduce the retention of activity in the kidneys, while avoiding long circulation time in the blood, is the optimization of labeling chemistry and residualizing properties of the label. Careful selection of peptide-based chelators, such as mercaptoacetyl- [12, 13, $41,42]$ or cysteine-containing chelators [13, 15, 16], for labeling of affibody molecules with technetium-99 $\mathrm{m}$ or rhenium-188/rhenium-186 enabled up to 50-fold lower retention in the kidneys compared with the parental structures $[14,17]$. However, due to the different chemical properties, many clinically promising radionuclides (e.g., ${ }^{177} \mathrm{Lu}$ ) cannot benefit from this approach.

For residualizing metal labels, one potential solution to the reuptake problem is to prevent glomerular filtration of the targeting protein by increasing its molecular weight. Fusion of $\mathrm{Z}_{\text {HER2:342 }}$ and $\mathrm{Z}_{\text {HER2:2891 }}$ affibody molecules with $A B D$ enabled efficient reduction of the kidney uptake and the higher dose delivered to the tumor than to the kidneys with ${ }^{177} \mathrm{Lu}[18,19]$. However, it is important to optimize the residence time of a radiolabeled conjugate in circulation to prevent irradiation of the radiosensitive bone marrow with this approach.

In this study, we have investigated whether the renal uptake of $\left[{ }^{99 \mathrm{~m}} \mathrm{Tc}\right] \mathrm{Tc}(\mathrm{CO})_{3}-\mathrm{G} 3$ DARPin could be reduced by the administration of compounds that act on various parts of the reabsorption system in the kidney.

Colchicine is an anti-gout drug that inhibits microtubule polymerization and disrupts intracellular trafficking of organelles in cells. Colchicine was shown to move megalin from the brush membrane to other intracellular compartments [43]. Administration of colchicine to rats leads to a decrease in the kidney uptake of $\left[{ }^{111} \mathrm{In}\right] \mathrm{In}$ DTPA-octreotide, which was additionally enhanced by co-injection of lysine [35].

Sodium maleate was also shown to affect the redistribution of megalin in the proximal tubules in rats [43]. Maleate reacts with succinyl-CoA, which leads to the inhibition of citric acid cycle and ATP production in tubular cells [44]. This results in inhibition of renal transport systems, including protein reabsorption in proximal convoluted tubule [45], and causes transient Fanconi syndrome [46, 47]. The administration of sodium maleate reduced the renal uptake of radiolabeled somatostatin analogs to $15 \%$ of the uptake in control [36].

Another compound that affects the ATP level in the kidneys is fructose. Parenteral administration of high doses of fructose leads to the sequestration of phosphates into metabolic intermediates and decreases ATP in the liver and kidneys [48]. A large dose of $40 \mathrm{mmol} /$ $\mathrm{kg}$ lowered ATP by $80 \%$ in the proximal straight tubule and by $60 \%$ in the proximal convoluted tubule. Twice lower dose of $20 \mathrm{mmol} / \mathrm{kg}$ caused a similar effect, by lowering ATP in straight and convoluted tubules by $76 \%$ and $41 \%$, respectively. Interestingly, the administration of $20 \mathrm{mmol} / \mathrm{kg}$ fructose did not affect the kidney uptake of $\left.{ }^{111} \mathrm{In}\right]$ In-DTPA-octreotide [35].

Probenecid is another anti-gout drug that inhibits organic anion transporter (OAT) and renal excretion of some drugs, thereby prolonging their half-life in the plasma. Stahl et al. reported that the use of probenecid reduced kidney uptake of $\left[{ }^{111} \mathrm{In}\right] \mathrm{In}$-DOTATOC by $30 \%$ [37]. That study also evaluated the effect of two types of diuretics, furosemide and mannitol, on reabsorption of $\left.{ }^{[111} \mathrm{In}\right]$ In-DOTATOC. Furosemide acts in the distal part of the loop of Henle, and mannitol is an osmotic diuretic. Furosemide administration led to a $44 \%$ increase in renal activity accumulation of $\left[{ }^{111} \mathrm{In}\right]$ In-DOTATOC, while mannitol had no effect.

In this study, autoradiography demonstrated mainly cortical accumulation of activity for all studied groups, which indicates the involvement of a (proximal) tubular mechanism in the reabsorption of $\left[{ }^{99 \mathrm{~m}} \mathrm{Tc}\right] \mathrm{Tc}(\mathrm{CO})_{3}-\mathrm{G} 3$, similar to other targeting radiolabeled proteins and peptides. However, lysine and Gelofusine, which were effective for reducing the kidney uptake of somatostatin peptides and nanobodies, did not decrease the kidney uptake of DARPins. We have observed similar results earlier for another class of ESPs, affibody molecules [33]. The administration of colchicine, which inhibits the recycling of megalin receptor to the cell surface, did not reduce the uptake of DARPins. Probenecid was not effective for lowering renal activity of G3, suggesting no contribution of organic anion transport to its renal reabsorption.

Similarly to the somatostatin analogs, the uptake of radiolabeled G3 and 9_29 DARPins in the kidneys was lowered by maleate. A high dose of fructose also reduced the renal uptake of G3. Although the exact mechanism of maleate or fructose action on renal reabsorption of proteins is not described, it could be speculated that these compounds cause a disruption of energy metabolism, lowering ATP-mediated uptake and endocytosis in proximal tubule cells. As the doses of maleate and 
fructose used in this study were high, it would further be of interest to see if lower doses or different administration schedules could provide a similar effect. As the degree of activity reduction provided by maleate and fructose would not be sufficient for potential application of DARPins for radionuclide therapy, the most promising strategies to reduce the activity uptake in the kidneys would be their fusion to ABD or pretargeting.

\section{Conclusion}

Common clinical strategies were not effective for the reduction of the kidney uptake of $\left[{ }^{99 \mathrm{~m}} \mathrm{Tc}\right] \mathrm{Tc}(\mathrm{CO})_{3}-\mathrm{G} 3$. Both fructose and maleate lower the cellular ATP level in proximal tubule cells, and their reduction of the kidney reuptake indicates the involvement of an ATPdriven mechanism of uptake. The decrease provided by maleate for both DARPins, G3, and 9_29, indicates that their uptake proceeds through a mechanism independent of DARPin structure and binding site composition. This knowledge could contribute to further understanding of the mechanisms behind the kidney reabsorption of radiolabeled ESPs.

\section{Abbreviations}

ATP: Adenosine triphosphate; DARPin: Designed ankyrin repeat protein; Gl: Gastrointestinal; i.p.: Intraperitoneal; i.v.: Intravenous; ID/g: Injected dose per gram; iTLC: Instant thin-layer chromatography; p.i.: Post-injection; PBS: Phosphate-buffered saline; SD: Standard deviation; SPECT: Single-photon emission computed tomography

\section{Acknowledgements}

The authors thank Prof. Anna Orlova for the excellent technical assistance.

\section{Authors' contributions}

MA, JG, and AV contributed to the concept and study design. AS performed the production and purification of proteins. SD supervised the production and purification of proteins. MA, JG, and SSR participated in planning and performing the in vivo experiments, data treatment, and interpretation. AV performed the labeling chemistry, in vivo studies, data treatment, and interpretation; coordinated the work; and wrote the manuscript. All authors revised the manuscript critically and read and approved the final manuscript.

\section{Funding}

This research was funded by Ministry of Science and Higher Education of the Russian Federation (075-15-2019-1925). Mohamed Altai's research activities were funded by the Swedish Society for Medical Research. The funders had no role in the study design, data collection and analysis, decision to publish, or preparation of the manuscript.

\section{Availability of data and materials}

All data generated or analyzed during this study are included in this published article.

\section{Ethics approval and consent to participate}

Animal studies were performed according to the Swedish national legislation on laboratory animal protection and were approved by the Ethical Committee for Animal Research in Uppsala.

\section{Consent for publication}

Not applicable.

\section{Competing interests}

The authors declare that they have no competing interests.

\section{Author details}

'Department of Immunology, Genetics and Pathology, Uppsala University, SE-75185 Uppsala, Sweden. 'Department of Medicinal Chemistry, Uppsala University, Uppsala, Sweden. ${ }^{3}$ Shemyakin-Ovchinnikov Institute of Bioorganic Chemistry, Russian Academy of Sciences, Moscow, Russia. ${ }^{4}$ National Research Tomsk Polytechnic University, Tomsk, Russia. ${ }^{5}$ Center of Biomedical

Engineering, Sechenov University, Moscow, Russia.

Received: 3 January 2020 Accepted: 17 January 2020

Published online: 04 February 2020

\section{References}

1. Krasniqi A, D'Huyvetter M, Devoogdt N, Frejd FY, Sörensen J, Orlova A, Keyaerts M, Tolmachev V. Same-day imaging using small proteins: clinical experience and translational prospects in oncology. J Nucl Med. 2018;59: 885-91.

2. Feldwisch J, Tolmachev V. Engineering of affibody molecules for therapy and diagnostics. Methods Mol Biol. 2012;899:103-26.

3. Lindbo S, Garousi J, Mitran B, Altai M, Buijs J, Orlova A, Hober S, Tolmachev $\checkmark$. Radionuclide tumor targeting using ADAPT scaffold proteins: aspects of label positioning and rResidualizing properties of the label. J Nucl Med. 2018;59:93-9.

4. Goldstein R, Sosabowski J, Livanos M, Leyton J, Vigor K, Bhavsar G, NagyDavidescu G, Rashid M, Miranda E, Yeung J, Tolner B, Plückthun A, Mather S, Meyer T, Chester K. Development of the designed ankyrin repeat protein (DARPin) G3 for HER2 molecular imaging. Eur J Nucl Med Mol Imaging. 2015;42:288-301.

5. Vorobyeva A, Bragina O, Altai M, Mitran B, Orlova A, Shulga A, Proshkina G, Chernov V, Tolmachev V, Deyev S. Comparative evaluation of radioiodine and technetium-labeled DARPin 9_29 for radionuclide molecular imaging of HER2 expression in malignant tumors. Contrast Media Mol Imaging. 2018; 2018:6930425

6. Deyev S, Vorobyeva A, Schulga A, Proshkina G, Güler R, Löfblom J, Mitran B, Garousi J, Altai M, Buijs J, Chernov V, Orlova A, Tolmachev V. Comparative evaluation of two DARPin variants: effect of affinity, size, and label on tumor targeting properties. Mol Pharm. 2019;3:995-1008.

7. Vorobyeva A, Schulga A, Konovalova E, Güler R, Löfblom J, Sandström M, Garousi J, Chernov V, Bragina O, Orlova A, Tolmachev V, Deyev SM. Optimal composition and position of histidine-containing tags improves biodistribution of 99mTc-labeled DARPin G3. Sci Rep. 2019;9:9405.

8. Vorobyeva A, Schulga A, Konovalova E, Güler R, Mitran B, Garousi J, Rinne SS, Löfblom J, Orlova A, Deyev S, Tolmachev V. Comparison of tumortargeting properties of directly and indirectly radioiodinated designed ankyrin repeat protein (DARPin) G3 variants for molecular imaging of HER2. Int J Oncol. 2019;4:1209-20.

9. Vorobyeva A, Schulga A, Rinne SS, Günther T, Orlova A, Deyev S, Tolmachev $V$. Indirect radioiodination of DARPin G3 using N-succinimidyl-paraiodobenzoate improves the contrast of HER2 molecular imaging. Int J Mol Sci. 2019;20:E3047.

10. Binz HK, Stumpp MT, Forrer P, Amstutz P, Pluckthun A. Designing repeat proteins: well-expressed, soluble and stable proteins from combinatorial libraries of consensus ankyrin repeat proteins. J Mol Biol. 2003;332:489-503.

11. Tolmachev $V$. Influence of labelling method on targeting properties. In: Stigbrand T, Carlsson J, Adams GP, editors. Targeted radionuclide tumor therapy. Netherlands: Springer; 2008. p. 158-64.

12. Ekblad T, Tran T, Orlova A, Widström C, Feldwisch J, Abrahmsén L, Wennborg A, Karlström AE, Tolmachev V. Development and preclinical characterisation of $99 \mathrm{mTc}$-labelled affibody molecules with reduced renal uptake. Eur J Nucl Med Mol Imaging. 2008;35:2245-55.

13. Tran T, Ekblad T, Orlova A, Sandström M, Feldwisch J, Wennborg A, Abrahmsén L, Tolmachev V, Eriksson KA. Effects of lysine-containing mercaptoacetyl-based chelators on the biodistribution of $99 \mathrm{mTc}$-labeled anti-HER2 affibody molecules. Bioconjug Chem. 2008;19:2568-76.

14. Orlova A, Tran TA, Ekblad T, Karlström AE, Tolmachev V. (186) RemaSGS-Z (HER2:342), a potential Affibody conjugate for systemic therapy of HER2-expressing tumours. Eur J Nucl Med Mol Imaging. 2010;37:260-9.

15. Ahlgren S, Wållberg $H$, Tran TA, Widström C, Hjertman M, Abrahmsén L, Berndorff D, Dinkelborg LM, Cyr JE, Feldwisch J, Orlova A, Tolmachev V. 
Targeting of HER2-expressing tumors with a site-specifically 99mTc-labeled recombinant affibody molecule, ZHER2:2395, with C-terminally engineered cysteine. J Nucl Med. 2009;50:781-9.

16. Wållberg H, Orlova A, Altai M, Hosseinimehr SJ, Widström C, Malmberg J, Ståhl S, Tolmachev V. Molecular design and optimization of 99mTc-labeled recombinant affibody molecules improves their biodistribution and imaging properties. J Nucl Med. 2011;52:461-9.

17. Altai M, Honarvar H, Wållberg H, Strand J, Varasteh Z, Rosestedt M, Orlova A, Dunås F, Sandström M, Löfblom J, Tolmachev V, Ståhl S. Selection of an optimal cysteine-containing peptide-based chelator for labeling of affibody molecules with (188) Re. Eur J Med Chem. 2014;87:519-28.

18. Tolmachev V, Orlova A, Pehrson R, Galli J, Baastrup B, Andersson K, Sandström M, Rosik D, Carlsson J, Lundqvist H, Wennborg A, Nilsson FY. Radionuclide therapy of HER2-positive microxenografts using a 177Lulabeled HER2-specific Affibody molecule. Cancer Res. 2007;67:2773-82.

19. Orlova A, Jonsson A, Rosik D, Lundqvist H, Lindborg M, Abrahmsen L, Ekblad C, Frejd FY, Tolmachev V. Site-specific radiometal labeling and improved biodistribution using ABY-027, a novel HER2-targeting affibody moleculealbumin-binding domain fusion protein. J Nucl Med. 2013;54:961-8.

20. Altai M, Membreno R, Cook B, Tolmachev V, Zeglis BM. Pretargeted imaging and therapy. J Nucl Med. 2017:58:1553-9.

21. Liu G, Mang'era K, Liu N, Gupta S, Rusckowski M, Hnatowich DJ. Tumor pretargeting in mice using ${ }^{99 \mathrm{~m} T} \mathrm{C}-$ labeled morpholino, a DNA analog. J Nucl Med. 2002:43:384-91.

22. Westerlund K, Altai M, Mitran B, Konijnenberg M, Oroujeni M, Atterby C, de Jong M, Orlova A, Mattsson J, Micke P, Karlström AE, Tolmachev V. Radionuclide therapy of HER2-expressing human xenografts using affibodybased peptide nucleic acid-mediated pretargeting: in vivo proof of principle. J Nucl Med. 2018;59:1092-8.

23. Rossin R, Verkerk PR, van den Bosch SM, Vulders RC, Verel I, Lub J, Robillard MS. In vivo chemistry for pretargeted tumor imaging in live mice. Angew Chem Int Ed Eng. 2010:49:3375-8.

24. Altai M, Perols A, Tsourma M, Mitran B, Honarvar H, Robillard M, Rossin R, ten Hoeve W, Lubberink M, Orlova A, Karlström AE, Tolmachev V. Feasibility of affibody-based bioorthogonal chemistry — mediated radionuclide pretargeting. J Nucl Med. 2016:57:431-6.

25. Goldenberg DM, Chang CH, Rossi EA, McBride JW, Sharkey RM. Pretargeted molecular imaging and radioimmunotherapy. Theranostics. 2012;2:523-40.

26. Forero A, Weiden PL, Vose JM, Knox SJ, LoBuglio AF, Hankins J, Goris ML, Picozzi VJ, Axworthy DB, Breitz HB, Sims RB, Ghalie RG, Shen S, Meredith RF. Phase 1 trial of a novel anti-CD20 fusion protein in pretargeted radioimmunotherapy for B-cell non-Hodgkin lymphoma. Blood. 2004;104: 227-36.

27. Bodet-Milin C, Faivre-Chauvet A, Carlier T, Rauscher A, Bourgeois M, Cerato E, Rohmer V, Couturier O, Drui D, Goldenberg DM, Sharkey RM, Barbet J, Kraeber-Bodere. Immuno-PET using anticarcinoembryonic antigen bispecific antibody and 68Ga-labeled peptide in metastatic medullary thyroid carcinoma: clinical optimization of the pretargeting parameters in a first-inhuman trial. J Nucl Med. 2016:57:1505-11.

28. Behr TM, Goldenberg DM, Becker W. Reducing the renal uptake of radiolabeled antibody fragments and peptides for diagnosis and therapy: present status, future prospects and limitations. Eur J Nucl Med. 1998;25: 201-12

29. Sörensen J, Sandberg D, Sandström M, Wennborg A, Feldwisch J, Tolmachev V, Åström G, Lubberink M, Garske-Román U, Carlsson J, Lindman H. First-in-human molecular imaging of HER2 expression in breast cancer metastases using the $111 \mathrm{ln}$-ABY-025 affibody molecule. $J$ Nucl Med. 2014;55:730-5.

30. Rolleman EJ, Valkema R, de Jong M, Kooij PP, Krenning EP. Safe and effective inhibition of renal uptake of radiolabeled octreotide by a combination of lysine and arginine. Eur J Nucl Med Mol Imaging. 2003;30:9-15.

31. Vegt E, Wetzels JF, Russel FG, Masereeuw R, Boerman OC, van Eerd JE, Corstens FH, Oyen WJ. Renal uptake of radiolabeled octreotide in human subjects is efficiently inhibited by succinylated gelatin. J Nucl Med. 2006;47:432-6.

32. Christensen El, Birn H. Megalin and cubilin: multifunctional endocytic receptors. Nat Rev Mol Cell Biol. 2002;3:256-66.

33. Altai M, Varasteh Z, Andersson K, Eek A, Boerman O, Orlova A. In vivo and in vitro studies on renal uptake of radiolabeled affibody molecules for imaging of HER2 expression in tumors. Cancer Biother Radiopharm. 2013:28:187-95.
34. Gainkam LO, Caveliers V, Devoogdt N. Localization, mechanism and reduction of renal retention of technetium-99m labeled epidermal growth factor receptor-specific nanobody in mice. Contrast Media Mol Imaging. 2011;6:85-92.

35. Rolleman EJ, Krenning EP, Van Gameren A, Bernard BF, De Jong M. Uptake of [111 ln-DTPA0] octreotide in the rat kidney is inhibited by colchicine and not by fructose. J Nucl Med. 2004;45:709-13.

36. Melis $\mathrm{M}$, Krenning EP, Bernard BF, Barone R, Visser TJ, de Jong $\mathrm{M}$. Localisation and mechanism of renal retention of radiolabelled somatostatin analogues. Eur J Nucl Med Mol Imaging. 2005:32:1136-43.

37. Stahl AR, Wagner B, Poethko T, Perutka M, Wester HJ, Essler M, Heemann U, Schwaiger M, Lutz J. Renal accumulation of [111ln] DOTATOC in rats: influence of inhibitors of the organic ion transport and diuretics. Eur J Nucl Med Mol Imaging. 2007;34:2129-34.

38. Jost C, Schilling J, Tamaskovic R, Schwill M, Honegger A, Plückthun A. Structural basis for eliciting a cytotoxic effect in HER2-overexpressing cancer cells via binding to the extracellular domain of HER2. Structure. 2013;21: 1979-91.

39. Christensen El, Birn H, Verroust P, Moestrup SK. Membrane receptors for endocytosis in the renal proximal tubule. Int Rev Cytol. 1998;180:237-84.

40. Nielsen S. Endocytosis in proximal tubule cells involves a two-phase membrane- recycling pathway. Am J Phys. 1993;264:C823-35.

41. Engfeldt T, Orlova A, Tran T, Bruskin A, Widström KAE, Tolmachev V. Imaging of HER2-expressing tumours using a synthetic affibody molecule containing the 99mTc-chelating mercaptoacetyl-glycyl-glycyl-glycyl (MAG3) sequence. Eur J Nucl Med Mol Imaging. 2007:34:722-33.

42. Tran TA, Rosik D, Abrahmsén L, Sandström M, Sjöberg A, Wållberg H, Ahlgren S, Orlova A, Tolmachev V. Design, synthesis and biological evaluation of a multifunctional HER2-specific Affibody molecule for molecular imaging. Eur J Nucl Med Mol Imaging. 2009;36:1864-73.

43. Christensen EI, Verroust PJ. Megalin and cubilin, role in proximal tubule function and during development. Pediatr Nephrol. 2002;17:993-9.

44. Rogulski J, Pacanis A. Effects of maleate on CoA metabolism in rat kidney. Curr Probl Clin Biochem. 1977;8:406-15.

45. Cho J, Galaske RG, Arbesman H, Van Liew JB. Renal albumin reabsorption in normal and sodium maleate-treated rats. Renal Physiol. 1985;5:8-18.

46. Harrison HE, Harrison HC. Experimental production of renal glycosuria, phosphaturia and aminoaciduria by injection of maleic acid. Science. 1954; 120:606-8.

47. Kramer HJ, Gonick HC. Experimental Fanconi syndrome. I. Effect of maleic acid on renal cortical NaK-ATPase activity and ATP levels. J Lab Clin Med. 1970;76:799-808.

48. Burch HB, Choi S, Dence CN, Alvey TR, Cole BR, Lowry OH. Metabolic effects of large fructose loads in different parts of the rat nephron. J Biol Chem. 1980;255:8239-44

\section{Publisher's Note}

Springer Nature remains neutral with regard to jurisdictional claims in published maps and institutional affiliations.

\section{Submit your manuscript to a SpringerOpen ${ }^{\circ}$ journal and benefit from:}

- Convenient online submission

- Rigorous peer review

- Open access: articles freely available online

High visibility within the field

- Retaining the copyright to your article

Submit your next manuscript at $\boldsymbol{\nabla}$ springeropen.com 